\title{
ERRATUM
}

\section{Assessing the capacity of the sympathetic nervous system to respond to a cardiovascular challenge in human spinal cord injury}

R Brown and VG Macefield

Spinal Cord (2009) 47, 426; doi:10.1038/sc.2009.4

Correction to: Spinal Cord (2008) 46, 666-672; doi:10.1038/ sc.2008.35; published online 8 April 2008

Since the publication of the above article, the authors have noticed that Figure 3 is incorrect.
The correct figure is shown below:

The typesetters would like to apologize for this mistake.
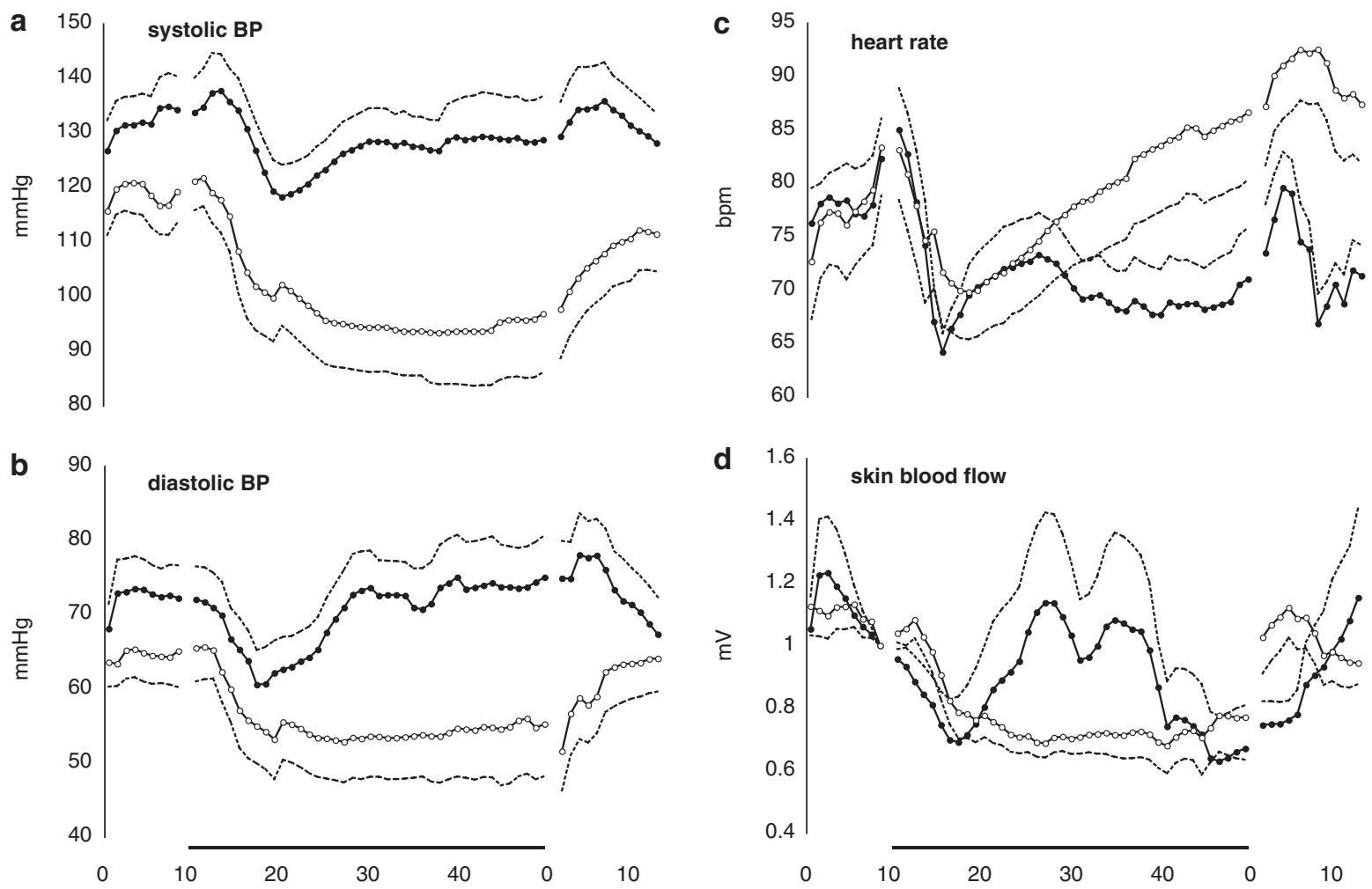

Figure 3 Average data from eight able-bodied subjects (filled circles) and thirteen spinal cord-injured subjects (open circles) at rest, during an inspiratory-capacity apnoea and during recovery. The dashed lines represent the standard errors. The numbers on the abscissa refer to the number of $\mathrm{R}$ waves. The black bar represents the period of the manoeuvre. Skin blood flow was recorded from the finger of able-bodied subjects and data from the toe are included from the spinal cord-injured subjects. 